\title{
Tecnologías disponibles para la Purificación de Biogás usado en la Generación Eléctrica
}

\author{
María T. Varnero ${ }^{(1)}$, Margarita Carú ${ }^{(2)}$, Karina Galleguillos ${ }^{(1)}$ y Patricio Achondo ${ }^{(1)}$ \\ (1) Universidad de Chile, Facultad de Ciencias Agronómicas, AGRIMED Casilla 1004, Santiago- \\ Chile. (e-mail:mvarnero@gmail.com; kgalleguillos@gmail.com; patricioachondo@yahoo.com) \\ (2) Universidad de Chile, Facultad de Ciencias. Casilla 1004, Santiago-Chile. \\ (e-mail:mcaru@codon.ciencias.uchile.cl)
}

Recibido Ago. 09, 2011; Aceptado Oct. 04, 2011; Versión Final recibida Ene. 04, 2012

\begin{abstract}
Resumen
Se resume y analiza algunas tecnologías que se han implementado para la purificación de biogás usado en la generación eléctrica. Se sabe que el biogás puede contener algunas impurezas y elementos traza que deben ser removidas antes de su uso en la matriz energética. Las tecnologías tradicionales para la purificación de biogás están basadas fundamentalmente en el empleo de métodos físicos y químicos, los cuales, además de generar contaminantes secundarios, a menudo tienen un alto costo. Como una alternativa, la purificación de biogás mediante procesos biológicos utilizando microorganismos parece atractiva. Los microorganismos pueden remover las sustancias consideradas contaminantes, especialmente para la eliminación de sulfuro de hidrógeno. Ser concluye que se trata de un método económico, con bajos gastos energéticos e inocuo para el medio ambiente y la salud humana.
\end{abstract}

Palabras clave: purificación, bioprocesos, biogás, biometano, biofiltros

\section{Available Technologies for Purification of Biogas used in Power Generation}

\begin{abstract}
Available technologies that have been implemented for biogas purification for its use in power generation are summarized and analyzed. It is known that biogas may contain some impurities and trace elements that must be removed before its use as energy source. Traditional technologies for biogas purification are based primarily on the use of physical and chemical methods, which, besides generating secondary pollutants, often have a high cost. As an alternative, biogas purification through biological processes using microorganisms has become attractive. The microorganisms can remove substances considered pollutants; especially they can remove hydrogen sulfide. It is concluded that the method is cost effective with low energy inputs and harmless to the environment and human health.
\end{abstract}

Keywords: purification, bioprocessing, biogas, biomethane, biofilters 


\section{INTRODUCCIÓN}

En Chile, el consumo de energías primarias se sustenta fundamentalmente en el uso de petróleo, gas natural y carbón, alcanzando un $76 \%$ del consumo total (CNE, 2005); mientras que sólo el $24 \%$ del consumo se originan a partir de energías renovables como hidroelectricidad y leña, siendo de esta manera despreciable la obtención de fuentes energéticas a partir del tratamiento de biomasa. En los últimos años, las condiciones para el desarrollo de las energías renovables no convencionales (ERNC), tales como la eólica, geotérmica, solar o de biomasa, han mejorado significativamente, siendo fundamental en este avance la promulgación de leyes, la implementación de instrumentos de apoyo directo a la inversión, la materialización de proyectos de inversión y la instauración de un debate nacional respecto de la importancia de una matriz energética diversificada y del rol que deben cumplir las ERNC en el suministro de energía en el futuro inmediato (Palma, et al., 2009).

En cuanto a la producción de electricidad, se han establecido cambios en la Ley General de Servicios Eléctricos (LGSE), oficializados en marzo de 2004 mediante la Ley 19.940, los que modifican un conjunto de aspectos de dicho mercado que afecta a todos los medios de generación, introduciendo elementos especialmente aplicables a las ERNC (Palma, et al., 2009). Entre otros, se establece entre los años 2010 y 2014, la obligación de suministrar energía en un $5 \%$, con medios renovables no convencionales. A partir de 2015 , este porcentaje se incrementará en $0,5 \%$ anual, hasta llegar al $10 \%$ en el año 2024 . La empresa eléctrica que no acredite el cumplimiento de esta obligación, deberá pagar un cargo por cada megawatt/hora de déficit respecto de su obligación (Palma, et al., 2009). Estas iniciativas legales, han permitido el desarrollo de posibles modelos de negocios debido a incentivos de mercado, lo que junto al alza de los precios de los combustibles fósiles en los mercados internacionales, permiten que inversionistas centren su atención en proyectos ERNC, especialmente en el mercado eléctrico. Dentro de las ERNC para el uso en el mercado de energía eléctrica, la biomasa presenta un notable potencial, definiéndose como la energía obtenida de la materia orgánica renovable de origen vegetal, animal o procedente de la transformación natural o artificial de la misma.

El biogás es un tipo de energía de biomasa, que se obtiene producto de la digestión anaeróbica o fermentación de la materia orgánica (residuos animales y vegetales) y que puede presentar diferentes usos energéticos, como calefacción, alumbrado o electricidad. Esta mezcla gaseosa, combustible, está compuesta por metano (55-70\%), anhídrido carbónico (30-45\%), más otros elementos traza tales como, oxígeno (200 ppm - 1\%), nitrógeno (menor a $5 \%$ ), vapor de agua y sulfuro de hidrógeno $(50 \mathrm{ppm}-3 \%)$. La concentración de los distintos gases en el biogás dependerá de la composición de las materias primas, las condiciones de descomposición, tiempo de retención hidráulica en el biodigestor, entre otros.

Dado que en Chile existen diferentes fuentes de biogás proveniente de rellenos sanitarios o de biodigestores anaeróbicos, entre otros, se hace indispensable promover el uso de esta energía y optimizar su eficiencia como combustible. Sin embargo, como el biogás puede contener algunas impurezas y elementos traza, debe ser purificado antes de ser inyectado a la red de gas natural, o para ser utilizado en la generación eléctrica. La remoción de $\mathrm{CO}_{2}, \mathrm{H}_{2} \mathrm{~S}$, vapor de agua, nitrógeno y oxígeno del biogás, permite obtener biometano, con una concentración de gas metano superior al $95 \%$, con lo cual, aumenta su poder calorífico. En el caso de su utilización para generación de electricidad, el elemento más perjudicial es el $\mathrm{H}_{2} \mathrm{~S}$, debido al elevado poder de corrosión que presenta, pudiendo dañar y disminuir la vida útil de motores, conversores y distintas maquinarias que intervienen en la producción, transferencia y suministro de energía eléctrica (Noyola, et al., 2006).

\section{PROBLEMAS DEL SULFURO DE HIDRÓGENO ASOCIADOS AL BIOGÁS}

El ácido sulfhídrico $\left(\mathrm{H}_{2} \mathrm{~S}\right)$ puede encontrarse en aguas estancadas, desagües y alcantarillados y es parte de la composición química de combustibles como el petróleo, gas natural e incluso del biogás, debido a que se produce por descomposición anaeróbica de restos orgánicos. La eliminación de este compuesto del biogás es relevante, pues este gas inflamable e incoloro, es 
altamente toxico y corrosivo, lo que constituye una gran desventaja, pues dificulta el traslado del gas por tuberías, su almacenamiento en tanques y otras estructuras metálicas, como aquellas que participan en la generación y distribución de electricidad (Pérez et al,. 2008).

Actualmente, existen tecnologías de purificación de biogás de tipo físico-químico, eficientes pero presentan altos costos de adquisición y de operación, y sólo en los últimos años se ha dado importancia a posibles métodos biológicos de purificación. Mediante éstos últimos, distintos tipos de microorganismos pueden utilizarse como agentes de transformación, conformando biofiltros con potencialidad de separar mezclas gaseosas, y de esta manera poder disminuir los altos costos presentados por los sistemas de purificación que emplean métodos físicos y químicos. Para eliminar el sulfuro de hidrógeno existen diferentes métodos basados en técnicas físico químicas (Pinjing et al., 2001) que se basan fundamentalmente en mecanismos de adsorción; absorción y método de filtración por membrana.

\section{Métodos de purificación por adsorción}

Los métodos de purificación por adsorción también llamados de lecho seco, se llevan a cabo sobre un material sólido fijo, sobre el cual el sulfuro de hidrógeno es adsorbido por adherencia. Por lo general, los materiales sólidos utilizados como adsorbentes son carbón activado, sílicagel y tamices moleculares de zeolitas o tamices moleculares de carbón (Llaneza, et al., 2010). Como el proceso de adsorción ocurre sobre la superficie del adsorbente, donde las moléculas son retenidas por fuerzas electrostáticas débiles, la reacción puede verse afectada por la humedad, selectividad, temperatura, presión y presencia de partículas.

El proceso de adsorción que requiere menos energía es cuando se utiliza carbón activado, porque opera con temperatura y presión menores, donde la reacción se realiza en los poros y el sulfuro de hidrógeno reacciona con el oxígeno produciendo azufre y agua (ecuación 1). El azufre donde el sulfuro de hidrógeno queda ocluido en los poros del carbón (Llaneza, et al., 2010).

$$
2 \mathrm{H}_{2} \mathrm{~S}_{(\mathrm{g})}+\mathrm{O}_{2(\mathrm{~g})} \rightarrow 1 / 4 \mathrm{~S}_{8(\mathrm{~s})}+2 \mathrm{H}_{2} \mathrm{O} \quad \Delta \mathrm{H}=-444 \mathrm{~kJ}
$$

La adsorción empleando sílicagel como indicador, también ha permitido la eliminación de sulfuro de hidrógeno y anhídrido carbónico (Llaneza et al., 2010). El cambio de coloración del compuesto indica la saturación del adsorbente que puede ser regenerado calentándolo a $117^{\circ} \mathrm{C}$.

La utilización de tamices moleculares, permite que el sistema opere a temperaturas cercanas a la ambiental. Estos pueden usarse para eliminar $\mathrm{H}_{2} \mathrm{~S}$, mercaptanos, agua y un buen número de otras impurezas. Los tamices moleculares compuestos de zeolita (López et al., 2009) con alta afinidad por las moléculas polares, presentan un área superficial de hasta $590 \mathrm{~cm}^{2} / \mathrm{g}$ teniendo tamaños de poros bien definidos lo que permite una remoción selectiva de diferentes compuestos.

En la actualidad, a nivel mundial la tecnología de purificación ampliamente usada se denomina "Pressure Swing Adsorption" (PSA) y puede utilizar tanto carbono activado como zeolitas o ambos. En este proceso de PSA, el anhídrido carbónico se separa del biogás utilizando procesos de adsorción/desorción a diferentes presiones. El sistema consta de cuatro recipientes llenos de material adsorbente. Durante el proceso, cada recipiente sigue un ciclo de presurizaciónadsorción-despresurización-desorción. Entonces el biogás entra por la parte inferior del recipiente y a medida que asciende, el material adsorbente capta tanto el anhídrido carbónico como el oxígeno y el nitrógeno, hasta obtenerse un gas con un $95 \%$ de $\mathrm{CH}_{4}$ y con una eficiencia de recuperación de metano presente en el biogás entre un $85 \%$ a $90 \%$ dependiendo del soporte o material adsorbente en el PSA (Mitariten, 2007). En el caso de utilizar titanio activado, se logra obtener las eficiencias más altas de recuperación de metano [Molecular Gate, Guild Associates Inc] (Mitariten, 2007). Cuando el material adsorbente de un recipiente está completamente saturado de los gases anhídrido carbónico, oxígeno y nitrógeno, la adsorción en ese recipiente deja de funcionar, entonces, el biogás pasa al siguiente recipiente, el cual previamente ha sido regenerado mediante despresurización a presión atmosférica (Schmack Biogas AG, 2005). Por 
otra parte, los sistemas de PSA dejan una pérdida gaseosa, llamada "gas de cola", que podría contener sulfuro de hidrógeno, anhídrido carbónico y gas metano, que debiera ser quemada, utilizando parte del metano que tiene el biogás. Esto representa un $12 \%$ del metano proveniente del biogás (en función del porcentaje de nitrógeno presente en el biogás a purificar y el material adsorbente). Además, los sistemas de PSA no remueven completamente el oxígeno (si se utiliza como material adsorbente; carbón activado o zeolitas), el cual representa un riesgo explosivo en presencia de gas metano y pérdidas en la recuperación del metano por oxidación a anhídrido carbónico. Los métodos de purificación por adsorción presentan la ventaja de ser muy efectivos en la reducción y remoción de contaminantes, sin embargo presentan costos de operación altos, debido al consumo eléctrico de los compresores que alcanza presiones de 100 [PSIG], por lo que su aplicación en países en vías de desarrollo se encuentra limitada (Fernández, 2004).

\section{Métodos de purificación por absorción}

Los métodos de purificación por absorción se utilizan ampliamente, debido a la eficiencia y reactividad del sulfuro con la mayoría de los metales (Horikawa et al., 2004). En otros casos, presentan costos relativamente bajos. Los sistemas más empleados son:

Absorción con compuestos de hierro: Se utilizan limallas de hierro colocadas en columnas de purificación que se encuentran humedecidas de forma discontinua con agua y rellenas con otro material por ejemplo, el aserrín; para ayudar a la hidrodinámica del sistema (Víquez, 2010). El proceso opera a distintas presiones, logrando eliminar eficientemente el $\mathrm{H}_{2} \mathrm{~S}$ a temperatura ambiente o superiores, con un contenido de humedad de las limallas entre 30 y $60 \%$, debiendo realizarse la operación a pH entre 7,5 y 8,5 . Es posible emplear óxido de hierro (III) hidratado para la purificación del biogás, adición de cloruro de hierro (III), utilización de pelets de hierro, utilización de residuos de la extracción de níquel, lavado con solución de hidróxido de sodio, así como también, otros sustratos "secos" tales como óxido de zinc, sólidos alcalinos, (Víquez, 2010), entre otros. También se ha utilizado hierro quelatado en fase líquida para la absorción del $\mathrm{H}_{2} \mathrm{~S}$ presente en el biogás.

Absorción con compuestos orgánicos: Diferentes compuestos orgánicos han sido utilizados para la purificación del biogás. Las soluciones de aminas (mono, di, tri etanol aminas o glicol aminas) se combinan por el grupo amino $\left[\left(\mathrm{NH}_{2}\right)\right]$ con $\mathrm{CO}_{2}$ y $\mathrm{H}_{2} \mathrm{~S}$ para dar hidrógeno carbonato de amonio $\left[\left(\mathrm{RNH}_{3}\right) \mathrm{HCO}_{3}\right]$ o sulfuros de amonio $\left[\left(\mathrm{RNH}_{3}\right)_{2} \mathrm{~S}\right]$ Las aminas se operan en procesos calientes debido a que el calor favorece la reacción química. Sin embargo, el calor excesivo puede causar vaporización y pérdida de la solución química. Por lo tanto, estos procesos operan usualmente a temperatura hasta $48^{\circ} \mathrm{C}$ (Fernández, 2004). La hidroxi-amino etilester es aún menos corrosiva y no forma espuma, de ahí que se prefiera para la purificación de gases.

Otros productos orgánicos utilizados para la reducción del contenido de $\mathrm{CO}_{2}$ y de $\mathrm{H}_{2} \mathrm{~S}$ en el biogás son el Towsend, en el que se emplea etilenglicol con dióxido de azufre y el Purox donde se aplica una solución de amonio de hidroquinona (Fernández, 2004). La regeneración del absorbente se lleva a cabo, usualmente, mediante calentamiento de la solución con disminución de la solubilidad y desprendimiento de un gas concentrado en sulfuro. El azufre puede recuperarse a partir de ese gas, quemando parte del sulfuro para obtener azufre elemental y dióxido de azufre, el sulfuro remanente se convierte, catalíticamente, en azufre elemental en presencia de óxido de aluminio. Debido a los costos de la mayoría de estas soluciones, este método de purificación se utiliza, fundamentalmente, en grandes instalaciones de producción de biogás, $\geq 15000 \mathrm{~m}^{3} / \mathrm{d}$, en países productores de dichas sustancias.

Absorción con agua: Este método se denomina también fregado o limpieza húmeda. El absorbente utilizado es el agua, el cual se pone en contacto con el biogás a purificar en torres 0 columnas (rellenas o no) donde se efectúa la transferencia de masa del $\mathrm{CO}_{2}$ y $\mathrm{H}_{2} \mathrm{~S}$ al agua que fluye a contracorriente. Las temperaturas de operación suelen ser de 5 a $10{ }^{\circ} \mathrm{C}$, aunque también se operan a temperatura ambiente, siendo las presiones de trabajo mayores de $1726 \mathrm{kPa}$. En este sistema se necesita regenerar el agua cargada de $\mathrm{CO}_{2}$ y $\mathrm{H}_{2} \mathrm{~S}$, lo que se realiza utilizando una torre donde, de forma instantánea, el $\mathrm{CO}_{2}$ y el $\mathrm{H}_{2} \mathrm{~S}$ pasan al aire circundante, reincorporando el agua al 
proceso de absorción; siendo necesario reponer entre 10 y $20 \%$ de ésta. Esta es una metodología poco eficiente por las temperaturas y altas presiones de trabajo, encareciendo los costos de operación.

\section{Método de filtración por membrana}

Este método tiene por objetivo "filtrar" el biogás (Fernández, 2004). Así la corriente gaseosa a purificar se desplaza a través de una membrana selectiva, debido a la fuerza motriz generada por diferencias de presión. El factor determinante es la permeabilidad que poseen las moléculas que componen la corriente de gas a purificar.

El proceso de permeación de un gas a través de una membrana polimérica no rugosa es un proceso complejo que puede involucrar varios pasos: 1) Adsorción del gas en una interfase de la membrana. 2) Solución del gas en la membrana en esa interfase. 3) Difusión activada del gas en, y a través de la membrana. 4) Desprendimiento del gas de la solución por la interfase opuesta. 5) Desorción del gas de la última interfase.

Los materiales de las membranas son formulados especialmente para separar selectivamente determinados gases, principalmente $\mathrm{CO}_{2}$ del $\mathrm{CH}_{4}$ presente en el biogás (Llaneza et al., 2010), siendo la permeabilidad de la membrana una función directa de la solubilidad química del gas específico en la membrana. Las membranas usadas hasta el presente son muy frágiles y tienen poros excesivamente pequeños, por lo que se requiere que el gas de entrada a las membranas esté limpio de material particulado. Estos sistemas son caros y generalmente se consideran no adecuados para aplicaciones a pequeña escala, aunque se han obtenido buenos resultados en estudios a nivel piloto.

\section{MÉTODOS BIOLÓGICOS PARA LA ELIMINACIÓN DE SULFURO DE HIDRÓGENO}

Además de las técnicas fisicoquímicas para la purificación de biogás, existen métodos biológicos o de biofiltración, que han sido probados a escala de laboratorio y piloto. Estos métodos, utilizan la capacidad metabólica de algunos microorganismos que degradan sustancias contaminantes. El uso de microorganismos (Soreanu et al., 2008) en la remoción de sulfuro de hidrógeno presente en el biogás, se basa en la oxidación microbiológica de $\mathrm{H}_{2} \mathrm{~S}$ a compuestos de azufre de fácil eliminación, como azufre elemental $\left(\mathrm{S}^{\circ}\right)$ o sulfatos $\left(\mathrm{SO}_{4}{ }^{-2}\right)$, fijando $\mathrm{CO}_{2}$ simultáneamente como función estequiométrica de la oxidación del sulfuro. De esta forma, se puede lograr un enriquecimiento en metano, al remover $\mathrm{CO}_{2}$ y eliminar el elemento $\left(\mathrm{H}_{2} \mathrm{~S}\right)$ más corrosivo y limitante respecto a usos posteriores del gas purificado.

La gran ventaja que presentan estas técnicas, respecto de los sistemas fisicoquímicos es la carencia de contaminantes secundarios, menores costos de inversión y operación por el bajo consumo de reactivos, menor consumo energético al poder trabajar a temperatura ambiente, altas eficiencias de degradación, biomasa inmovilizada en el sistema (Pérez y Villa, 2005). Sin embargo, el procedimiento es lento, siendo necesario buscar nuevos microorganismos que reduzcan los tiempos de residencia y hagan más competitivo el proceso a nivel industrial.

Estos sistemas biológicos, utilizan bioreactores o biofiltros de amplio uso (Soreanu et al., 2005) para degradar contaminantes orgánicos como inorgánicos de una corriente gaseosa. En estos biofiltros se ubican los cultivos puros o mixtos de microorganismos (Singh y Mandal, 2011). Dependiendo de la cepa responsable (Madigan et al., 2006), se podría convertir sulfuros a azufre o alternativamente a sulfato, como se indica en las ecuaciones 2 y 3.

$\mathrm{CO}_{2}+2 \mathrm{H}_{2} \mathrm{~S} \rightarrow\left[\mathrm{CH}_{2} \mathrm{O}\right]+2 \mathrm{~S}^{\circ}+\mathrm{H}_{2} \mathrm{O}$

$2 \mathrm{CO}_{2}+\mathrm{H}_{2} \mathrm{~S}+2 \mathrm{H}_{2} \mathrm{O} \rightarrow 2\left[\mathrm{CH}_{2} \mathrm{O}\right]+\mathrm{H}_{2} \mathrm{SO}_{4}$ 
Existe una variedad de bacterias que oxidan el sulfuro de hidrógeno y, por lo tanto, pueden ser utilizadas como potenciales candidatos para la tecnología de desulfuración del gas (Friedrich et al., 2001; Syed et al., 2006). Se encuentran bacterias aerobias azufre oxidantes tanto en condiciones alcalinas, neutras como ácidas, con rangos de temperatura de crecimiento mesófilo y termófilo; que pertenecen a géneros como Acidianus, Acidithiobacillus, Aquaspirilum, Aquifex, Bacillus, Beggiota, Methylobacterium, Paracoccus Pseudomonas, Starkeya, Sulfolobus, Thermitiobacillus, Thiobacillus y Xanthobacter. En cambio, las bacterias anaerobias azufre oxidante son comúnmente neutrófilas y mesófilas de géneros como Allochromatium, Chlorobium, Rhodopseudomonas, Rhodovulum y Thiocapsa. (Friedrich et al., 2001). En cuanto a necesidades de fuente de energía y de carbono, se pueden distinguir los siguientes grupos:

Fotoautotrofos, diversos estudios (Prescott, et al., 2003) demuestran que bacterias fototróficas del tipo "bacteria verde sulfurosa", tal como Chlorobium limícola, remueve $\mathrm{H}_{2} \mathrm{~S}$ en presencia de luz, $\mathrm{CO}_{2}$ y nutrientes inorgánicos bajo condiciones estrictamente anaeróbicas, hasta la formación de azufre (ecuación 2) o de sulfato (ecuación 3).

Quimiolitotrofos o Quimioautótrofos, los cuales fijan $\mathrm{CO}_{2}$ como fuente de carbón y obtienen energía celular de la oxidación de compuestos inorgánicos, sin la necesidad de luz. Sin embargo, se tiene que evitar la oxidación de metano presente en biogás en concentraciones igual o mayor que la de $\mathrm{CO}_{2}$. Por lo tanto, se tiene que fijar $\mathrm{CO}_{2}$ bajo condiciones estrictamente anaeróbicas. Se logra la asimilación de $\mathrm{CO}_{2}$ por quimioautótrofos mediante el Ciclo de Calvin-Benson en ausencia de luz.

Mixotrofos, microorganismos que presentan metabolismo facultativo, pudiendo usar una fuente de carbono orgánica o inorgánica y la oxidación de compuestos inorgánicos reducidos como fuentes de energía (Syed et al., 2006).

Los principales microorganismos estudiados y que se emplean para la desulfuración, corresponden a los géneros Beggiatoa, Xanthomonas Sulfolobus, Lectospirillum y, especialmente, Chlorobium y Thiobacillus (Kleerebezem y Mendez, 2002). Uno de los géneros más estudiados para la purificación de sulfuro de hidrógeno, corresponde a la cepa Pseudomona putida $\mathrm{CH} 11$ aislada desde aguas residuales agrícolas con un pH óptimo entre 6 y 8 . Se evalúo, que el principal producto metabólico de la oxidación del sulfuro de hidrógeno fue azufre elemental. Cuando fue inmovilizada en alginato de calcio, las células exhibieron una alta eficiencia de remoción del sulfuro de hidrógeno, que excedieron al 96 por ciento, a concentraciones de sulfuro de hidrógeno desde 10 hasta 150 partes por millón (ppm). La cepa inmovilizada tiene un alto potencial para ser usada como agente para la remoción del sulfuro de hidrógeno (Valencia, 2002).

Otro de los géneros que destacan por los estudios realizados corresponde a Thiobacillus. Es así como, Soreanu et al (2008), informan que se operó un sistema biológico anóxico, diseñado para tratar biogás y se inoculó con Thiobacillus denitrificans como parte de un consorcio cultivado de microorganismos, obtenidos a partir de lodo recuperado de una planta de tratamiento de aguas sanitarias, y enriquecido en nitrato. Se logró un nivel de remoción de $\mathrm{H}_{2} \mathrm{~S}$ de casi $100 \%$ durante un plazo operativo de 3,5 meses, lo que representa un tiempo de remoción excesivo, atribuible al hecho de trabajar con cultivos puros, con una bacteria específica. Esto se podría revertir utilizando cultivos mixtos (Soreanu et al., 2005). Se asumió que el microorganismo desnitrificador, T. denitrificans, facilitó las transformaciones indicadas en ecuación 4.

$\mathrm{H}_{2} \mathrm{~S}+\mathrm{CO}_{2}+$ Nutrientes $\rightarrow$ celdas $+\mathrm{S}^{\circ}\left(\mathrm{o} \mathrm{SO}_{4}{ }^{-2}\right)+\mathrm{NO}_{2} \mathrm{y} / \mathrm{o} \mathrm{N}_{2}$

Sin embargo, para evitar la oxidación de metano, se tendría que operar el sistema biológico bajo condiciones estrictamente anaeróbicas y además inhibir a la enzima metano monooxidasa (MMO), responsable de la oxidación, mediante la adición de inhibidores conocidos, como amonio, nitrato y nitrito. Los estudios que demuestran que nitrato, nitrito y el ion de amonio actúan como inhibidores de MMO y la oxidación de metano, señalan niveles de inhibición con cinéticas tipo Michaelis- 
Menton (Campos, et al., 2008). Esto permite disponer de un aceptor de electrones para la cepa, facilitando las conversiones químicas deseadas y evitando la transformación no deseada. Bacterias clasificadas como denitrificadores, como por ejemplo, cepas de los géneros Clostridium, y Bacillus entre otras, podrían facilitar la fijación de $\mathrm{CO}_{2}$, la oxidación de sulfuros y reducción de nitrato a nitrito. Esta situación tiene lugar, ya que, reductores de sulfato, a veces pueden coexistir con oxidantes de sulfuros, regenerando el donador de electrones utilizado por microogarnismos denitrificadores en la reducción de $\mathrm{CO}_{2}$.

Al realizar pruebas con Pseudomonas putida (S1), Citrobacter sp. (S4) y Enterobacter sp. (S5), Valencia (2002) observó la decoloración del efluente en un $97 \%$; además se redujo la $\mathrm{DBO}_{5}$, la DQO, compuestos fenólicos y el sulfuro de hidrógeno. Este último hasta un $96,67 \%$ en 24 horas de aireación. Se han empleado cultivos puros de células de Thiobacillus thiooxidans JCM 7814 (Rattanapan y Ounsaneha, 2011) utilizando como agente tampón el citrato de sodio. Otra alternativa es el empleo de bacterias fotosintéticas como la Chlorobium limícola (Friedrich et al., 2001) y la forma de Thiosulfatophilum las cuales pueden convertir el sulfuro de hidrógeno a azufre elemental o sulfato. Posee altas velocidades de remoción, simples requerimientos de nutrientes y no necesita oxígeno ni esterilización. Este tipo de bacterias absorbe la mayor cantidad de luz cercana a longitudes de onda de 460 y 760 nanómetros $(\mathrm{nm})$.

\section{Diseño de filtros biológicos para la purificación de biogas}

Los microorganismos descritos anteriormente, necesitan de un soporte donde se puedan llevar a cabo los procesos y vías metabólicas. Para ello, existen sistemas que permiten que los microorganismos seleccionados, que se encuentren inmovilizados o en suspensión, mineralicen los compuestos a tratar. Los sistemas más utilizados son los biolavadores, biofiltros de lecho fijo (BLF) y biofiltros de lechos escurrido.

\section{Biolavadores (Bioscrubbers)}

Los biolavadores presentan dos etapas de desarrollo: en la primera se realiza un proceso de absorción y en la segunda, que se efectúa con un reactor biológico, la etapa de regeneración. En la etapa de absorción, los contaminantes se extraen mediante la absorción con agua en una torre de aspersión o columna. En la segunda etapa, el liquido recircula al reactor biológico en donde se lleva a cabo la oxidación, por microorganismos que pueden encontrarse libres o inmovilizados. Una vez reducida la concentración del contaminante en el líquido, éste es reciclado al absorbedor (Revah y Ortiz, 2004).

\section{Biofiltros de lecho fijo}

En estos biofiltros el flujo de gas a tratar debe pasar por un "reactor" que contenga un material de soporte fijo y poroso que debe estar humedecido, que es lugar donde se desarrollará la película de microorganismos. El contaminante es transferido desde el gas a esta biopelícula húmeda en donde es transformado eventualmente en $\mathrm{CO}_{2}$ y $\mathrm{H}_{2} \mathrm{O}$, siendo estos compuestos arrastrados a la salida (Revah y Ortiz, 2004). Este tratamiento previo permite una saturación rápida de los contaminantes contenidos en el biogás y permite determinar el reemplazo o reciclaje de la fase líquida en el proceso. En el año 2005, más de 300 biofiltros se instalaron y quedaron operativos en EE.UU. La gran mayoría se diseñó para el tratamiento de emisiones gaseosas contaminantes provenientes de plantas de tratamiento de aguas sanitarias. En estos sistemas, generalmente el flujo de gas se pasa previamente por un humificador con el fin de mantener la humedad del sistema.

Los materiales utilizados como matriz de soporte pueden ser diferentes tipos de compost, desechos de madera, turba, bagazo de caña, cáscaras de cacahuate, entre otros (MorganSagustume y Noyola, 2006). Estos soportes normalmente contienen los suficientes minerales para sostener una población adecuada aunque la adición controlada de nutrientes, y agua tienen un efecto estimulante. También se han estudiado soportes inertes, como materiales cerámicos, entre otros, en donde los nutrientes tienen que ser adicionados externamente. En general, estos 
materiales deben presentar una alta porosidad y fuerza compresiva. Para minimizar problemas operativos resultantes de la compactación del relleno, los biofiltros se construyen en sectores con una altura de no más de 1,2 m., con el objetivo de limitar el aumento de presión a través del biofiltro a $10 \mathrm{~cm}$. de la columna de agua.

La eficiencia de remoción de partículas, dependerá de varios factores relacionados con el diseño de los biofiltros y las propiedades de los contaminantes presentes en el gas a tratar. El coeficiente de Henry y las solubilidades en agua son propiedades de los contaminantes que deben considerarse para lograr una remoción eficiente. La eficiencia de remoción del $\mathrm{H}_{2} \mathrm{~S}$, lograda por los biofiltros oscila entre un 90 y un $100 \%$. La eficiencia de remoción lograda por los compuestos orgánicos volátiles (VOCs), en general oscila entre un 20 a un 90\%, incluso con aquellos contaminantes fácilmente biodegradable como el tolueno y la acetona.

\section{Biofiltros de escurrimiento (biotrickling filters)}

Los biofiltros de escurrimiento (biotrickling filters) operan en forma similar a biofiltros, aunque en los de escurrimiento, se introduce una fase líquida enriquecida en nutrientes a las camas de relleno o lechos de soporte, compuestas de material inerte y sintético, o bien, de material natural como rocas volcánicas, suelo (Cohen, 2001). La solución introducida contiene nutrientes inorgánicos esenciales, tales como nitrógeno, fósforo, potasio, sodio, entre otros, y dicha solución puede ser reciclada luego de ser utilizada. Aunque los biofiltros de escurrimiento son más complejos que los filtros convencionales, usualmente son más efectivos, especialmente en el tratamiento de compuestos difíciles de descomponer o compuestos que generan productos secundarios, tales como $\mathrm{H}_{2} \mathrm{~S}$. En general, los filtros de escurrimiento (Soreanu et al., 2008) se construyen a mayor altura que los biofiltros y son sistemas que presentan un mayor control debido a que la fase liquida introducida se transporta y remueve las celdas muertas y productos solubles y insolubles. Se ha comprobado que ambos tipos de biofiltros son tecnologías efectivas en la remoción de $\mathrm{H}_{2} \mathrm{~S}$ y olores asociados con emisiones gaseosas provenientes de plantas de tratamiento de aguas sanitarias. Si bien, los biofiltros escurridos no se han empleado a la misma escala industrial que los convencionales, la prospección que presenta ésta tecnología es alentadora. La tecnología asociada a los filtros de escurrimiento ha sido aplicada exitosamente descomponiendo hidrocarburos alifáticos y aromáticos, compuestos de cloruros y compuestos inorgánicos.

La concentración de nutrientes que debe ser agregada en la solución, se basa en los requerimientos del consorcio microbiano (Maestre et al., 2010) y razones estequiométricas, aunque generalmente se requieren niveles de nutrientes bastantes menores a los esperados en base a la estequiometría, debido al reciclaje de nutrientes que se realiza respecto a células muertas, biodigestión de biomasa acumulada, entre otros. Además, se deben mantener las concentraciones de sales y productos de metabolismo menores que los niveles inhibitorios.

En la mayoría de casos, la solución se trasporta a través del filtro y es reciclada, aunque en ciertos casos, el número de reciclajes posibles es limitado. Los filtros funcionan mejor cuando la película biológica es parcialmente humedecida, sugiriendo que los contaminantes se transfieren de la fase gaseosa a la película bacteriana directamente. Por otra parte, se tiene que elegir cuidadosamente el soplador para tener una operación económicamente efectiva, tanto en los biofiltros convencionales como en los de escurrimiento. Cuando se realizan grandes aplicaciones, se recomienda un soplador con un "drive" de velocidad variable. Aunque estos modelos son más caros que aquellos de drive con velocidad fija, permiten ajustes respecto a cambios en flujos y presiones, que se producen debido a la biomasa. Los modelos con "drives" de velocidad variable evitan la necesidad de regulación y control de flujo. Se puede instalar un soplador tipo "forced draft" upstream o un soplador tipo "induced draft" downstream.

La mayoría de la descomposición lograda por los filtros ocurre en la película bacteriana, aunque en ciertos casos, un nivel de actividad significativa se encuentra en la fase líquida reciclada. La remoción de contaminantes es el resultado de una combinación compleja de transferencias de masa, difusión, convección y procesos biológicos. Todos los factores afectan las condiciones 
operativas del sistema y también influyen en la eficiencia de remoción de contaminantes, como en las condiciones, las cinéticas y dinámicas del filtro.

\section{CONCLUSIONES}

A través de la recopilación de antecedentes e información, es posible observar que existe gran interés por desarrollar alternativas para la eliminación de sulfuro de hidrógeno de la composición del biogás, para que éste pueda ser utilizado adecuadamente y sin restricciones en la matriz energética. Dentro de las distintas y posibles alternativas, los métodos biológicos destacan pues no generan un remanente contaminante del tipo "gas de cola" o "tail gas". Además, como las presiones de trabajo no superan los 7 [Bar], presentan menores costos de operación, si se considera que la relación de presión es directamente proporcional al consumo eléctrico del compresor. Esto significa una mayor eficiencia energética.

\section{AGRADECIMIENTOS}

Los autores agradecen a CONICYT por el financiamiento otorgado para la realización de este trabajo a través del proyecto FONDEF $\mathrm{N}^{\circ} \mathrm{D} 07 / 1008$.

\section{REFERENCIAS}

Campos, J. y otros cuatros autores. Kinetics of denitrification using sulphur compounds: Effects of $\mathrm{S} / \mathrm{N}$ ratio, endogenous and exogenous compounds. Bioresource Technology 99: 1293-1299, (2008).

Cohen, Y. Biofiltration - the treatment of fluids by microorganisms immobilized into the filter bedding material: a review. Bioresource Technology 77 (3), 257 -274, (2001)

Comisión Nacional de Energía (CNE). Balance energético Nacional. Disponible en línea http://www.cne.cl/estadisticas/ Acceso: 15 junio de 2011. (2005).

Fernández, E. Procedimiento para la purificación de biogás. Instituto Superior Politécnico José Antonio Echeverria. Publicación CU 23003 Al. Oficina Cubana de la Propiedad Intelectual. Habana, Cuba. 18 p. (2004).

Friedrich CG y otros cuatro autores. Oxidation of reduced inorganic sulfur compounds by bacteria: Emerge of a common mechanism? Applied and Environmental Microbiology 67 (7), 2873 - 2882 (2001).

Horikawa, M. y otros cuatro autores. Chemical absortion of $\mathrm{H}_{2} \mathrm{~S}$ for biogas purification. Braz. J. Chem. Eng. 3 (21), $415-422$, (2004).

Kleerebezem, R. y Mendez, R. . Autotrophic denitrification for combined hydrogen sulfide removal from biogas and post-denitrification. Water Science and Technology 45: 349-356. (2002).

López, C., y otros tres autores Avances en Química 4(3), 113-125 (2009).

Llaneza, H. y otros tres autores. Estudio de viabilidad de sistemas de purificación y aprovechameinto de biogás. Cap. 1. Caracterización, purificación y control del biogás. PSE PROBIOGAS: 1-28 (2010).

Madigan, M.; Martinko, J.; Parker, J. Brock. Biología de los microorganismos. Pearson Educación, S.A. $10^{\circ} E d$., Madrid, España, 1089p. (2006).

Maestre, JP. y otros seis autores. Bacterial community analysis of a gas-phase biotrickling filter for biogas mimics desulfurization through the rRNA approach. Chemosphere; 80(8):872-80. (2010). 
Mitariten, M. Landfill gas upgranding process. USPTO Applicaton 20070068386. class 095116000.(2007). Disponible en: http://www.moleculargate.com. Acceso: 22 de diciembre de 2011.

Morgan-Sagustume, JM. y Noyola, A. Hydrogen sulfide removal by compost biofiltration: Effect of mixing the filter media on operational factors. Bioresource Technology 97 (13), 1546, (2006).

Noyola, A., Morgan-Sagastume, J.M.y López-Hernández, J.E. Treatment of biogas produced in anaerobic reactors for domestic wastewater: odor control and energy/resource recovery. Rev. Environ Sci. Biotechnol. 5: 93-114 (2006).

Palma, R.; Jiménez, G.; Alarcón, I. Las Energías Renovables No Convencionales en el Mercado Eléctrico Chileno. Proyecto Energías Renovables No Convencionales (CNE/GTZ) 124 pp. (2009).

Pérez, H. y Villa, P. Desulfuración biológica: una alternativa para el tratamiento de emisiones de gases a la atmosfera. Agua Latinoamericana. Vol. 5 (3): 17-20. (2005).

Pérez, M. y otros tres autores. Utilización de biogás en pilas de combustible. Centro de Investigaciones Energéticas, Medioambientales y Tecnológicas. España, 68 p. (2008)

Pinjing, Hy otros tres autores. Removal of hydrogen sulfide and methyl mercaptan by a packed tower with immobilized micro-organism beads. Water Science Technology. Vol. 44 (9): 327-33; (2001).

Prescott, L.M.; Harley, J.P. y Klein, D.A. Microbiology. (Fifth Edition), McGraw-Hill Companies, 1026 p. (2003).

Rattanapan, C. y Ounsaneha, W. Removal of Hydrogen Sulfide Gas using Biofiltration - a Review. Walailak Journal of Science and Technology (WJST), North America, 10, nov. 2011. Disponible en: http://wjst.wu.ac.th/index.php/wjst/article/view/22. Acceso: 22 de diciembre de 2011.

Revah S. y Ortíz I. "El desarrollo de bioprocesos para el tratamiento de aire contaminado emitido por fuentes fijas." En "Fundamentos y Casos Exitosos de la Biotecnología Moderna" Francisco Bolivar Ed. El Colegio Nacional México. Pp 625- 658, (2004).

Schmack Biogas AG. Biogas Purification - Conditioning, cleaning and enriching of methane (2005). Disponible en: http://www.schmack-biogas.com. Acceso: 15 de Junio de 2011.

Singh, R. \& Mandal S.K. Microbial Removal of Hydrogen Sulfide from Biogas. Energy Sources;

Part A: Recovery, Utilization, and Environmental Effects. Vol. 34, Issue 4, 306-315, 2011

Soreanu, G.; Al-Jamal, M. y Béland, M. Biogas treatment using an anaerobic biosystem. In Proceedings of $3^{\text {rd }}$ Canadian Organic Residuals and Biosolids Management Conference, 502 513. Calgar, AB (2005).

Soreanu G. y otros cuatro autores. Laboratory pilot scale study for $\mathrm{H}_{2} \mathrm{~S}$ removal from biogas in an anoxic biotrickling filter". Water Sci. Technol. 57 (2), 201-207, (2008).

Syed, M. y otros tres autores. Removal of hydrogen sulfide from gas streams using biological processes. A review. Canadian Biosystems Engineering. 48: 2.1-2.14 (2006).

Valencia, R. Reducción del sulfuro de hidrógeno en el biogás, empleando como fuentes de microorganismos las aguas residuales de las fábricas de azúcar y de destilerías de alcohol. Tesis de diploma. Facultad de Ingeniería. ISP JAE. .Universidad de La Habana. (2002).

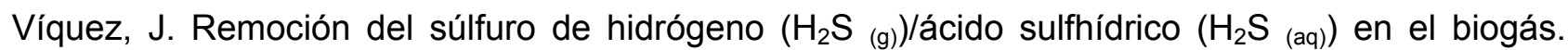
ECAG N53, 16-21 (2010). 